Kieft, R.A.M.M., Vreeke, E.M., Groot, E.M. de, Graaf-Vaar, H.I. de, Gool, C.H. van, Koster, N., Napel, H. ten, Francke, A.L., Delnoij, D.M.J. Mapping the Dutch SNOMED CT subset to Omaha System, NANDA International and International classification of Functioning, Disability anef 7 Health.

\begin{tabular}{|c|c|}
\hline $\begin{array}{l}\text { Postprint } \\
\text { Version }\end{array}$ & 1.0 \\
\hline Journal website & $\begin{array}{l}\text { https://www.sciencedirect.com/science/article/pii/S1386505617304768?via\%3Dih } \\
\underline{\mathrm{ub}}\end{array}$ \\
\hline Pubmed link & https://www.ncbi.nlm.nih.gov/pubmed/29425638 \\
\hline DOI & 10.1016/j.jijmedinf.2017.12.025 \\
\hline
\end{tabular}

This is a NIVEL certified Post Print, more info at http://www.nivel.eu

\title{
Mapping the Dutch SNOMED CT subset to Omaha System, NANDA International and International Classification of Functioning, Disability and Health
}

R.A.M.M. KIEFT, E.M. VREEKE, E.M. DE GROOT, H.I. DE GRAAF-WAAR, C.H. VAN GOOL, N. KoSTER, H. TEN NAPEL, A.L. FRANCKE AND D.M.J. DELNOIJ

\section{HighLights}

- Multiple classifications are used across healthcare settings. Difficulties arise when nurses want to share and compare information.

- A Dutch nursing subset of SNOMED CT patient problems has been determined.

- Its purpose is to develop comparable terms that are used throughout the care sector and can therefore be exchanged.

- The present study is designed to link SNOMED CT patient problems to three classifications.

- The findings should make an important contribution to the exchange of nursing information across healthcare settings.

\footnotetext{
AbSTRACT

Background

Nurses register data in electronic health records, which can use various terminology and coding systems. The net result is that information cannot be exchanged and reused properly, for example when a patient is transferred from one care setting to another. A nursing subset of patient problems was therefore developed in the Netherlands, based on comparable and exchangeable terms that are used throughout the healthcare sector and elsewhere (semantic interoperability).

The purpose of the current research is to develop a mapping between the subset of patient problems and three classifications in order to improve the exchangeability of data. Those classifications are the Omaha System, NANDA International, and ICF (the International Classification of Functioning, Disability and Health).

Method

Descriptive research using a unidirectional mapping strategy.

Results
} 
Kieft, R.A.M.M., Vreeke, E.M., Groot, E.M. de, Graaf-Vaar, H.I. de, Gool, C.H. van, Koster, N., Napel, H. ten, Francke, A.L., Delnoij, D.M.J. Mapping the Dutch SNOMED CT subset to Omaha System, NANDA International and International classification of Functioning, Disability anef Health.

Some $30 \%-39 \%$ of the 119 SNOMED CT patient problems can be mapped oneto-one from the subset onto each separate classification. Between $6 \%$ and $8 \%$ have been mapped partially to a related term. This is considered to be a one-toone mapping, although the meanings do not correspond fully. Additionally, $23 \%-51 \%$ of the patient problems could be mapped n-to-one, i.e. more specifically than the classification. Some loss of information will always occur in such exchanges. Between $1 \%$ and $4 \%$ of the patient problems from the subset are defined less specifically than the problems within the individual classifications. Finally, it turns out that $9 \%-32 \%$ of the terms from the subset of patient problems could not be mapped onto a classification, either because they did not occur in the classification or because they could not be mapped at a higher level.

Conclusion

To promote the exchange of data, the subset of patient problems has been mapped onto three classifications. Loss of information occurs in most cases when the patient problems are transformed from the subset into a classification. This arises because the classifications are different in structure and in the degree of detail. Structural cooperation between suppliers, healthcare organisations and the experts involved is required in order to determine how the mapping should be used within the electronic health records, and whether it is usable in day-today practice.

\section{INTRODUCTION}

Various classifications are used in nursing practice for recording nursing data in the electronic health records [ 1,2 ], which means that problems or nursing diagnoses, interventions and results/outcomes are systematically grouped together, defined and encoded. The advantage is that nurses will be arranging their data in the same way and using the same language when data is recorded. This applies equally in Dutch nursing practice. For instance, 72 home care organisations and 22 software suppliers are members of the Omaha System Support foundation [ 3 ], which issues certificates determining whether the basic rules of the Omaha System have been met. There are also organisations and software suppliers that use the classifications for nursing diagnoses (from NANDA International; NANDA-I), interventions (the Nursing Intervention Classification; NIC) and nursing outcomes (Nursing Outcome Classification; NOC) (NNN) and the International Classification of Functioning, Disability and Health (ICF). However, is not known how many organisations have integrated these classifications into their electronic health records. This reveals that there is a diversity of nursing data [ 4 ].

Various reports have been published that discuss the consequences of this variability: information cannot be exchanged and reused properly, for example when a patient is transferred from one care setting to another [ 5,6]. The nursing transfer report is often still given to the patient in paper form. Even when data is transferred digitally, there is no direct integration into the electronic care file of the receiving care organisation: the data still has to be input manually [ $4,7,8$ ]. Comparable findings have been observed in international studies into the transfer and reuse of data [ 910 $1112]$. 
Kieft, R.A.M.M., Vreeke, E.M., Groot, E.M. de, Graaf-Vaar, H.I. de, Gool, C.H. van, Koster, N., Napel, H. ten, Francke, A.L., Delnoij, D.M.J. Mapping the Dutch SNOMED CT subset to Omaha System, NANDA International and International classification of Functioning, Disability anet 7 Health.

To help solve these problems, a nursing subset of 119 patient problems has been determined in the Netherlands: its purpose is to develop comparable terms that are used throughout the care sector and can therefore be exchanged [ 13 ]. The patient problems have been encoded using the SNOMED CT reference terminology [ 14 ]. The focus of this reference terminology is the use of the term and associated synonyms. Links to the classifications can be made, also known as 'mapping' [ 15 ]. A mapping process checks whether a term from one classification or terminology system matches or is comparable to a term in another classification or terminology system [ 16 ]. In this regard, a distinction is made between source terms and target terms. The source terms are the data that has been described and encoded using an encoding system from which the map is to be constructed. The target terms are the data of the encoding system into which mapping takes place.

The purpose of this investigation is to develop a mapping from the subset of patient problems to three classifications that are used in the Netherlands (the Omaha System, NANDA-I and ICF) to allow automated interchange of data and to increase the comparability of data. The 119 patient problems from the subset were the source terms and the problems or diagnoses of the classifications were the target terms. Research questions:

To what extent can the SNOMED CT subset of patient problems be mapped onto the:

- Omaha System?

- NANDA International diagnosis tables?

- ICF?

\section{METHOD}

\subsection{Research design}

Descriptive research using a unidirectional strategy based on manual semantic mapping.

A unidirectional strategy means that source terms are only mapped onto target terms [ 17,18 ]. Semantic mapping means that the meaning and definition of the terms are considered for similarities of certain features. If specific features correspond, the terms can be mapped onto one another [ 192021 ]. Vomiting, retching and emesis are for instance associated terms, because their meaning is the same.

\subsection{Sample, composition and data collection}

\subsubsection{Sample}

The following source documents and releases were used for the mapping:

- Dutch subset of patient problems [Dutch and English version] (January 2017 release) ( https://www.nictiz.nl/terminologiecentrum/referentielijsten/nationalekernset )

- SNOMED International browser (January 2017 release)

- The Omaha System [ 22 ] and Het Omaha System; Een introductie [ 23 ]

- NANDA International, English version, 2015-2017 edition [24 ] and Dutch translation of the 2012-2014 edition [ 25 ]

- ICF, Dutch translation (2007) [ 26 ] and ICF browser 2008-2016 [ 27 ]

The mapping was based on both the Dutch and English versions; the Dutch source documents were used for the Dutch mapping. The English versions of the 
Kieft, R.A.M.M., Vreeke, E.M., Groot, E.M. de, Graaf-Vaar, H.I. de, Gool, C.H. van, Koster, N., Napel, H. ten, Francke, A.L., Delnoij, D.M.J. Mapping the Dutch SNOMED CT subset to Omaha System, NANDA International and International classification of Functioning, Disability anef 7 Health.

classifications or terminologies were consulted for the associated encoding to make sure that the codes and associated terms corresponded.

\subsubsection{Composition}

Three separate expert groups were set up for the mapping process; one for each classification system.

The experts involved met with the following requirements:

- a nursing, IT and/or scientific background

- extensive knowledge of at least one specific classification (NANDA-I, Omaha System, ICF, SNOMED CT terminology)

- involvement in the development of a classification or terminology and/or experts in the implementation of a classification or terminology in electronic medical records

\subsubsection{Data collection}

The mapping method was based on the ISO model 18104, which has been defined by the European Committee for Standardization (CEN). This model breaks patient problems down into (a) a clinical finding, such as pain or (b) a focus (drinking) with a judgement (difficulty) [ 28 ]. This detailing made it possible to objectify the similarities and differences between the terms to be mapped. The method was used in various studies and considered to be appropriate [ 293031 ].

In order to structure the mapping process, an Excel file was set up in which three features were determined successively for the subset of patient problems and classifications: Dutch and English terms, the Dutch and English definitions and the associated codes (see Appendix A in Supplementary material).

Each classification has a hierarchy and an encoding system of its own that is decisive for the way that mapping could be done.

The Omaha System defines 42 areas of concern or problems that are mostly described neutrally, each with three possible different attributes: actual, potential or health-promotion. Each area of concern with the attribute 'actual' has a set of unique signs/symptoms for that state [ 22 ]. Patient problems were mapped by both actual and potential areas of concern. For each area of concern, the table (Appendix A in Supplementary material) states whether it is an actual (A) or potential (P) problem. The NANDA-I classification comprises 148 concepts that are specified further into 235 standardised nursing diagnoses, grouped into 13 domains and 47 classes (20152017 edition). The domains and classes have not been encoded in the documentation used for this study. The nursing diagnoses are encoded and defined [ 24 ] and contain aetiological factors and the signs and symptoms or risk factors. The mapping onto the NANDA-I diagnoses was done at the level of the diagnosis labels, including determining whether the definition of the nursing diagnosis matched the definition of the patient problem.

The ICF has four domains, each of which is subdivided into seventeen chapters (categories). The chapters in turn are broken down into classes and sub-classes. All these levels (domains, chapters, classes and sub-classes) are encoded and defined [ 26 ] and were used for the mapping. ICF does not use a status for 'potential' or 'risk of', which is why the mapping took place at three levels: 'impairment', 'participation restriction' or 'difficulty', quantified by a scale of 'mild', 'moderate', 'severe' or 'complete'. 
Kieft, R.A.M.M., Vreeke, E.M., Groot, E.M. de, Graaf-Vaar, H.I. de, Gool, C.H. van, Koster, N., Napel, H. ten, Francke, A.L., Delnoij, D.M.J. Mapping the Dutch SNOMED CT subset to Omaha System, NANDA International and International classification of Functioning, Disability anet 7 Health.

The patient problems of the subset are based on SNOMED CT. The hierarchy and structure of the classifications were considered during the mapping, along with how they relate to the SNOMED CT hierarchy.

\subsection{Data analysis}

Two experts (EV and $E G)$ determined which target terms from a classification matched the source terms of the subset. For this analysis the following mapping relationships were used [ 18 ]:

- one-to-one mapping : the meaning of the target term is entirely the same as the source term. The source and target terms are immediately exchangeable without any loss of information.

- partial mapping : the source and target terms are not exactly the same, but their meanings correspond partially and are related.

- one-to-n mapping : the source term is less detailed than the target term. More than one target term can be linked to the same source term.

- n-to -one mapping: the source term is more detailed than the target term. More than one source term can be linked to the same target term.

- one-to-none mapping : no target term is found for the source term.

The results were discussed with the third expert (RK) and recorded in an Excel file and was then sent by e-mail to the experts of the relevant classifications for an initial remote consultation round. After that, the experts were invited to attend face-to-face mapping meetings for each classification, at which each patient problem and its mapping proposal was discussed. The separate mapping meetings took place between September 2016 and January 2017.

After the meeting, the resulting table was presented by e-mail to the experts in question for review. The mappings were discussed until a consensus had been reached. In order to reach a consensus, it was possible to modify the patient problem term used within SNOMED CT, or to add further detail to the associated definition. A colour code was given to the term after the consensus (For interpretation of the references to colour in the text, the reader is referred to the web version of this article.):

\section{[FIGURE 1]}

Once the mapping had been approved by all experts, the separate tables were merged into a single table (Appendix A in Supplementary material).

\section{RESULTS}

For each mapping type, Table 1 states how many of the 119 patient problems of the subset were semantically mapped onto the classifications. Appendix A in Supplementary material gives an explanation of the mapping results.

\section{[TABLE 1]}

\subsection{The Omaha System}

Thirty-six of the 119 patient problems from the subset (30\%) turned out to be synonymous with problems within the Omaha System (see Appendix A in Supplementary material, green colour codes). An example is "incontinence of faeces" (subset) and 'incontinent of stool' (Omaha System). 
Kieft, R.A.M.M., Vreeke, E.M., Groot, E.M. de, Graaf-Vaar, H.I. de, Gool, C.H. van, Koster, N., Napel, H. ten, Francke, A.L., Delnoij, D.M.J. Mapping the Dutch SNOMED CT subset to Omaha System, NANDA International and International classification of Functioning, Disability anet 7 Health.

Additionally, the terms for seven patient problems (6\%) partially matched. An example is 'diversional activity deficit' (subset) and 'minimal outside stimulation/leisure time activities', within 'social contact' as an actual problem (Omaha System). The problems overlap: both are issues involving leisure time, but leisure time activities can also refer to activities at home.

There are four (3\%) patient problems that the Omaha System is more specific about than the subset (one-to-n mapping) (see Table 2 ).

\section{[TABLE 2]}

Sixty-one out of the 119 patient problems from the subset (51\%) are more specific than the areas of concern or signs/symptoms from the Omaha System. Thirty-seven out of these 61 patient problems have been mapped onto one area of concern. An example is 'dyspnoea' (subset) which has been mapped to the 'respiration' area of concern (Omaha System). Although that the patient problem is fully covered by the area of concern, it is neither identical nor included as a synonym within the Omaha System as a sign/symptom. In addition, 24 patient problems are part of a sign/symptom. Some patient problems have been mapped onto the same sign/symptom. For example, one of the signs/symptoms within the 'skin' area of concern is a 'lesion/pressure ulcer'. Various types of wounds (such as burns to the skin and pressure sores) have been included in the subset, which are then all mapped using the same 'lesion/pressure ulcer' symptom. In these cases, the patient problems are more specific than the signs/symptoms.

No suitable single area of concern or sign/symptom was found in the Omaha System for 11 patient problems (9\%). These included 'inadequate social support', 'impaired home maintenance management', 'difficulty coping' and 'low self-control' - see Appendix A in Supplementary material.

\subsection{The NANDA-I diagnoses}

42 of the 119 patient problems (35\%) turned out to be one-to-one comparable with a NANDA-I diagnosis, such as 'difficulty performing toileting activities' (subset) and 'toileting self-care deficit' (NANDA-I diagnosis).

A partial mapping for the NANDA-I A diagnosis was determined for 7 patient problems (6\%). An example is 'victim of abuse' (subset) and 'risk of post traumatic syndrome' (NANDA-I diagnosis). Although being a victim of abuse is a risk factor for post-traumatic syndrome, it is not the same as the risk itself.

There are five patient problems (4\%), such as 'urinary incontinence', 'fluid imbalance' and 'difficulty coping', where the NANDA-I diagnoses is more specific than the patient problems from the subset (see Appendix A in Supplementary material).

Additionally, 27 patient problems from the subset (23\%) were mapped to a higher level (n-to-one mapping). One example is 'physical aggression' and 'verbal aggression' (subset) which are mapped using the same NANDA-I diagnosis, 'risk of violence directed at others'. Other comparable examples are the patient problems 'burn to the skin', 'eruption of the skin' and 'eczema'. These are all mapped using the 'impaired skin integrity' NANDA-I diagnosis.

No corresponding or related NANDA-I diagnoses were found for $38(32 \%)$ of the patient problems. Examples are 'disorientated', 'manic mood', and 'housing problems'. 
Kieft, R.A.M.M., Vreeke, E.M., Groot, E.M. de, Graaf-Vaar, H.I. de, Gool, C.H. van, Koster, N., Napel, H. ten, Francke, A.L., Delnoij, D.M.J. Mapping the Dutch SNOMED CT subset to Omaha System, NANDA International and International classification of Functioning, Disability anef 7 Health.

\subsection{ICF}

Forty-seven of the 119 patient problems (39\%) turned out to be one-to-one comparable to an ICF target term. An example is 'pain'.

Nine patient problems $(8 \%)$ were mapped as 'partial'. An example is 'difficulty coping' from the subset, which is linked to problems with 'cognitive flexibility \& handling stress and other psychological demands' (ICF).

One patient problem (1\%), 'sexuality-related problem' (subset), has been mapped into two more specific terms in the ICF, namely 'sexual functions' and 'intimate relationships' (see also Appendix A in Supplementary material).

Fifty patient problems from the subset (42\%) are more specific than the problems from the ICF, such as 'aphasia' (subset) and 'mental functions of language' (ICF). No corresponding terms were found for twelve of the patient problems $(10 \%)$. Examples are: 'feeling lonely', 'at risk of loneliness', 'at risk of undernutrition' (see also Appendix A in Supplementary material).

\section{DISCUSSION}

The purpose of this study was to develop a mapping between the SNOMED CT subset of patient problems onto three classification systems. This national mapping is important for nursing practice in order to improve the exchangeability of data. The patient problems have been mapped to the classifications using a unidirectional mapping. Various studies into mapping data have been performed [ 17, 29, 323334 3536 ], but to our knowledge, no validated national or international SNOMED CT mappings to an NANDA-I, Omaha System or ICF classification in either direction have been defined by the organisations involved (IHTSDO, Omaha System,

NANDA-I and the World Health Organization (ICF)).

Our study shows that there is a lot of variation between classifications in structure and in the degree of detail. This influences whether or not terms from the subset of patient problems can be mapped. The highest percentage of one-to-one relationships was with the ICF at 39\%, as against $30 \%$ for the Omaha System and 35\% for the NANDA-I diagnoses. Despite these superficially comparable percentages of between $30 \%$ and $39 \%$, in most cases a patient problem that has a one-to-one relationship in one classification does not in the other classifications. A total of six of the 119 patient problems (5\%) were mapped one-to-one in all three classification systems. These are:

- abnormal body temperature

- difficulty performing toileting activities

- difficulty performing washing and drying activities

- difficulty transferring location

- incontinence of feces

- ineffective breathing pattern

Only these six patient problems can always be interchanged; information loss occurs in all other cases. If we look at studies about mapping data, comparable results are described: exchange is possible, but loss of information will occur [ 35,36 ]. Another finding is that various patient problems get mapped to a higher hierarchic level that is encoded as an 42 area of concern (Omaha System) or 17 chapters (ICF). The NANDA-I diagnoses are grouped into 13 domains and 47 classes. These domains and classes (2015-2017 edition), in the documentation used for this study, are not encoded. Therefore, it was not possible to map the patient problems of the 
Kieft, R.A.M.M., Vreeke, E.M., Groot, E.M. de, Graaf-Vaar, H.I. de, Gool, C.H. van, Koster, N., Napel, H. ten, Francke, A.L., Delnoij, D.M.J. Mapping the Dutch SNOMED CT subset to Omaha System, NANDA International and International classification of Functioning, Disability anet 7 Health.

subset to the higher hierarchic domains or classes. It is possible that this is the reason why the percentage of patient problems one-to-none mapping is highest for the NANDA-I at $32 \%$, as compared to the $9 \%$ for the Omaha System and $11 \%$ for ICF. In our opinion, how these one-to-n or n-to-one relationships should be dealt with depends on the purpose of the mapping, namely data exchange: whatever is transferred from system A to system B must be interpreted correctly by the receiving party. That principle has guided the way the mapping has done. For example, if the sending party states that a 'sexuality-related problem' (subset) is involved, will the receiving party be able to translate this into one of the more specific terms 'ineffective sexuality pattern' and 'sexual dysfunction' (NANDA-I diagnoses)? It is important to determine, together with the suppliers and users, if any options are possible and practical for making sure data can be exchanged without interpretation errors. In addition, rules should be drawn up for suppliers and users when the mapping is used. For the quality of the mapping it is also important to evaluate those rules in terms of the risk of incorrect interpretation and loss of information. As far as we know, little research has been performed into implementing mapping in electronic medical records and the effects of mapping on data exchange.

\subsection{Implications for nursing practice}

This study showed how complex mapping between multiple classifications can be. In order to utilise the potential of this mapping, we believe that structural cooperation with suppliers, care organisations and the experts involved is required to ensure interchangeability of the data used by nurses in their day-to-day practice. It is also important to determine, together with nurses, whether further detailing is required and how this further detailing relates to other classifications. If, for instance, the various types of urinary incontinence (NANDA-I diagnoses) are added to the national subset, the addition will also affect the mapping to the Omaha System or the ICF. This is because these specifications are not included in those classifications. It is important to determine through practical research which patient problems are most frequently exchanged and which specifications are required.

\subsection{Research strengths and limitations}

A key strength of this study was that the experts involved had extensive knowledge of and also were involved in the development of at least one specific classification. Nevertheless, determining the mapping types is also a process between experts: between $6 \%$ and $8 \%$ of the patient problems were mapped partially as a result of consensus between the experts. This could be a limitation. On the other hand, the method for mapping was based on ISO model 18104 [ 28 ], which made it possible to unravel patient problems so that the experts could determine the mapping as objectively as possible.

Although we have performed an extensive unidirectional mapping process, a bidirectional mapping is required in order to exchange information. This might be a possible limitation. Bidirectional mapping also reverses the process: the source terms become target terms and a map is constructed in the reverse direction too [ 17, 18 ]. The advantage is that this makes exchanges possible in both directions. However, bidirectional mapping is complex as one-to-n relationships are involved in many situations. In these situations, the sender has to determine whether the target terms are interpreted correctly by the receiving party, or whether the source term should be 
Kieft, R.A.M.M., Vreeke, E.M., Groot, E.M. de, Graaf-Vaar, H.I. de, Gool, C.H. van, Koster, N., Napel, H. ten, Francke, A.L., Delnoij, D.M.J. Mapping the Dutch SNOMED CT subset to Omaha System, NANDA International and International classification of Functioning, Disability anef 7 Health.

retained. Therefore unidirectional mapping is necessary and an important first step in order to exchange data and to increase the comparability of data.

\section{CONCLUSION}

This study mapped the Dutch subset of patient problems onto three classifications in order to enable automated exchange of digital data. Information loss occurs in most cases if patient problems are exchanged without supplementary information being added. In total, only six of the 119 patient problems (5\%) have been mapped one-toone in all the classifications. This is because the classifications differ in terms of their structures and the degree of detail at various levels. Structural cooperation between the suppliers, nursing organisations and experts involved is therefore required in order to evaluate whether the mapping is usable in day-to-day practice.

\section{CONTRIBUTIONS BY THE AUTHORS}

RK, EV and EG helped design the study, helped in the data collection and -analysis phase. $\mathrm{HGW}, \mathrm{CvG}, \mathrm{NK}$ and $\mathrm{HtN}$ helped collect and analyse the data, and have provided comments on the article. ALF and DD helped design the structure of the study and formulate the research questions, helped draw up the article and provided comments on it.

\section{STATEMENT ON CONFLICTS OF INTEREST}

The authors declare that they have no conflicting interests. This study has not received any specific subsidies from public, commercial or non-profit organisations. What do we know?

- Different terms in nursing practice and data cannot always be exchanged properly

- A Dutch SNOMED CT subset has been developed to make digital exchange possible

- A mapping is required if data is to be exchanged with systems using classifications What has been learned from this research?

- The results of mapping against SNOMED CT are different for each classification

- Only six of the patient problems are always exchangeable

- In most cases, information loss will occur

- Cooperation between suppliers, experts and nurses is required

\section{REFERENCES}

[1]. Thoroddsen A., Ehrenberg A., Sermeus W., and Saranto K.: A survey of nursing documentation, terminologies and standards in European countries. Nurs. Inform. 2012; 406:

View In Article

[2]. Westra B.L., Delaney C.W., Konicek D., and Keenan G.: Nursing standards to support the electronic health record. Nurs. Outlook 2008; 56:

View In Article

[3]. Omaha System NL, 24-12-2016. (2016). http://www.omahasystem.nl/omaha/partners-enleden.html (Accessed 5 November 2017).

View In Article

[4]. J. Krijgsman, I. Swinkels, B. Lettow van, J. de Jong, K. Out, R. Friele, L. Gennip van, Meer dan techniek. eHealth-monitor 2016, Den Haag, 2016.

View In Article 
Kieft, R.A.M.M., Vreeke, E.M., Groot, E.M. de, Graaf-Vaar, H.I. de, Gool, C.H. van, Koster, N., Napel, H. ten, Francke, A.L., Delnoij, D.M.J. Mapping the Dutch SNOMED CT subset to Omaha System, NANDA International and International classification of Functioning, Disability ane Health.

[5]. Ministerie van Volksgezondheid Welzijn en Sport (VWS), Terugdringen registratielasten in de langdurige zorg, Den Haag, 2014.

View In Article

[6]. Nederlandse Federatie van Universitair medische centra (NFU), Registratie aan de bron. Visie op documentatie en gebruik van zorggegevens 2013-2020, 2013.

View In Article

[7]. Inspectie voor Gezondheidszorg (IGZ), Continuïteit van zorg voor kwetsbare ouderen vanuit het ziekenhuis naar verpleeg-en verzorgingshuizen, thuiszorg en huisartsen niet gewaarborgd, Utrecht, 2015.

View In Article

[8]. Nictiz, De verpleegkundige overdracht in beweging, Den Haag, 2017. https://www.nictiz.nl/Paginas/Onderzoeksrapport\%20vpk\%20overdracht\%20DEFINITIEF.p df.

View In Article

[9]. Griffiths D., Morphet J., Innes K., Crawford K., and Williams A.: Communication between residential aged care facilities and the emergency department: a review of the literature. Int. J. Nurs. Stud. 2014; 51: pp. 1517-1523

View In Article | Cross Ref

[10]. Morphet J., Griffiths D.L., Innes K., Crawford K., Crow S., and Williams A.: Shortfalls in residents' transfer documentation: challenges for emergency department staff, Australas. Emerg. Nurs. J. 2014; 17: pp. 98-105 View In Article | Cross Ref

[11]. Holly C., and Poletick E.B.: A systematic review on the transfer of information during nurse transitions in care. J. Clin. Nurs. 2014; 23: pp. 2387-2396

View In Article | Cross Ref

[12]. Samal L., Dykes P.C., Greenberg J.O., Hasan O., Venkatesh A.K., Volk L.A., and Bates D.W.: Care coordination gaps due to lack of interoperability in the United States: a qualitative study and literature review. BMC Health Serv. Res. 2016; 16: pp. 143 View In Article

[13]. R. Kieft, E. Vreeke, E. de Groot, P. Volkert, A. Francke, D. Delnoij, The development of a nursing subset of patient problems to support interoperability [Not published] (2017). View In Article

[14]. SNOMED International, (2017). http://www.snomed.org/ (Accessed 16 June 2017). View In Article

[15]. Cornet R., and de Keizer N.: Forty years of SNOMED: a literature review. BMC Med. Inform. Decis. Mak. 2008; 8:

View In Article

[16]. IHTSDO, SNOMED CT Starter Guide, Snomed. (2014) 1-56.

http://doc.ihtsdo.org/download/doc_StarterGuide_Current-en-GB_INT_20141202.pdf. View In Article

[17]. Wieteck P.: Furthering the development of standardized nursing terminology through an ENP-ICNP cross-mapping. Int. Nurs. Rev. 2008; 55: pp. 296-304

View In Article | Cross Ref

[18]. Juvé Udina M.-E., Gonzalez Samartino M., and Matud Calvo C.: Mapping the diagnosis axis of an interface terminology to the NANDA international taxonomy. ISRN Nurs. 2012; undefined: pp. 1-6

View In Article

[19]. Saitwal H., Qing D., Jones S., Bernstam E.V., Chute C.G., and Johnson T.R.: Crossterminology mapping challenges: a demonstration using medication terminological systems. J. Biomed. Inform. 2012; 45: pp. 613-625

View In Article | Cross Ref

[20]. Fung K.W., Bodenreider O., Aronson A., Hole W., and Srinivasan S.: Combining lexical and semantic methods of inter-terminology mapping using the UMLS. Stud. Health Technol. Inform. 2007; 129: pp. 606-609 View In Article

[21]. Kim T.Y., Coenen A., and Hardiker N.: Semantic mappings and locality of nursing diagnostic concepts in UMLS. J. Biomed. Inform. 2012; 45: pp. 93-100

View In Article | Cross Ref 
Kieft, R.A.M.M., Vreeke, E.M., Groot, E.M. de, Graaf-Vaar, H.I. de, Gool, C.H. van, Koster, N., Napel, H. ten, Francke, A.L., Delnoij, D.M.J. Mapping the Dutch SNOMED CT subset to Omaha System, NANDA International and International classification of Functioning, Disability ane Health.

[22]. Martin K.: The Omaha System: A Key to Practice, Documentation and Information Management. Omaha, NE: Health Connection Press, 2005.

View In Article

[23]. N. Koster, J. Harmsen, Het Omaha System; Een introductie, 1e ed, 6e, Perquery bv, 2016.

View In Article

[24]. In Herdman T., and Kamitsuru S. (eds): NANDA International Nursing Diagnoses: Definitions and Classification, 2015-2017. Oxford: Wiley-Blackwell, West-Sussex, United Kingdom, 2014.

View In Article

[25]. Herdman T.: Nanda International. Verpleegkundige diagnoses en classificaties 20122014. Houten: Bohn Stafleu van Loghum, 2014.

View In Article

[26]. Nederlands WHO-FIC Collaborating Centre (RIVM), Nederlandse vertaling van de International Classification of Functioning, Disability and Health, Second, Bohn Stafleu van Loghum, Houten, 2007.

View In Article

[27]. ICF browser, (2016). http://apps.who.int/classifications/icfbrowser/ (Accessed 16 June 2017).

View In Article

[28]. ISO 18104:2014, Health Informatics - Categorial structures for representation of nursing diagnoses and nursing actions in terminological systems, (2014).

http://www.iso.org/iso/iso_catalogue/catalogue_tc/catalogue_detail.htm?csnumber=59431. View In Article

[29]. Bakken S., Warren J.J., Lundberg C., Casey A., Correia C., Konicek D., and Zingo C.: An evaluation of the usefulness of two terminology models for integrating nursing diagnosis concepts into SNOMED Clinical Terms . Int. J. Med. Inform.. pp. 71-77

View In Article | Cross Ref

[30]. Hwang J.I., Cimino J.J., and Bakken S.: Integrating nursing diagnostic concepts into the medical entities dictionary using the ISO reference terminology model for nursing diagnosis. J. Am. Med. Inform. Assoc. 2003; 10: pp. 382-388

View In Article | Cross Ref

[31]. Bakken S., Warren J.J., Lundberg C., Casey A., Correia C., Konicek D., and Zingo C.: An evaluation of the utility of the CEN categorial structure for nursing diagnoses as a terminology model for integrating nursing diagnosis concepts into SNOMED. Stud. Health Technol. Inform.. pp. 151-155

View In Article

[32]. Matney S.A., DaDamio R., Couderc C., Dlugos M., Evans J., Gianonne G., Haskell R., Hardiker N., Coenen A., and Saba V.K.: Translation and integration of CCC nursing diagnoses into ICNP. J. Am. Med. Inform. Assoc. 2008; 15: pp. 791-793

View In Article | Cross Ref

[33]. Hyun S., and Park H.A.: Cross-mapping the ICNP with NANDA, HHCC, Omaha system and NIC for unified nursing language system development. Int. Nurs. Rev. 2002; 49: pp.

99-110

View In Article | Cross Ref

[34]. Hyun S., Park H.A., Kim T.Y., Hardiker N.R., Coenen A., Casey A., Coenen A., and Konicek D.: Inter-terminology mapping of nursing problems. Int. Nurs. Rev. 2002; 49: pp. 319-323

View In Article

[35]. Monsen K.A., Finn R.S., Fleming T.E., Garner E.J., LaValla A.J., and Riemer J.G.: Rigor in electronic health record knowledge representation: lessons learned from a SNOMED CT clinical content encoding exercise. Inform. Health Soc. Care 2016; 41: pp. 97-111 View In Article

[36]. Goossen W.: Cross-mapping between three terminologies with the international standard nursing reference terminology model. Int. J. Nurs. Terminol. Classif. 2006; 17: pp. 153-164 
Kieft, R.A.M.M., Vreeke, E.M., Groot, E.M. de, Graaf-Vaar, H.I. de, Gool, C.H. van, Koster, N., Napel, H. ten, Francke, A.L., Delnoij, D.M.J. Mapping the Dutch SNOMED CT subset to Omaha System, NANDA International and International classification of Functioning, Disability anef 7 Health.

\section{[TABLES AND FIGURES]}

Figure 1

\section{- one-to-one mapping}

- partial mapping

- one-to-n mapping

- $\quad$-to-one mapping

- one-to-none mapping

Table 1

Overview of the degree to which patient problems could be mapped onto classifications.

\begin{tabular}{llllll}
\hline Vocabulary & \multicolumn{2}{l}{ Total patient problems (subset) N 119} & \\
\cline { 2 - 6 } & $\begin{array}{l}\text { one-to-one } \\
\text { mapping }\end{array}$ & $\begin{array}{l}\text { partial } \\
\text { mapping }\end{array}$ & $\begin{array}{l}\text { one-to-n } \\
\text { mapping }\end{array}$ & $\begin{array}{l}\text { n-to-one } \\
\text { mapping }\end{array}$ & $\begin{array}{l}\text { one-to- } \\
\text { none } \\
\text { mapping }\end{array}$ \\
\hline $\begin{array}{c}\text { Omaha } \\
\text { System }\end{array}$ & $36(30 \%)$ & $7(6 \%)$ & $4(3 \%)$ & $61(51 \%)$ & $11(9 \%)$ \\
$\begin{array}{c}\text { NANDA-I } \\
\text { diagnoses }\end{array}$ & $42(35 \%)$ & $7(6 \%)$ & $5(4 \%)$ & $27(23 \%)$ & $38(32 \%)$ \\
ICF & $47(39 \%)$ & $9(8 \%)$ & $1(1 \%)$ & $50(42 \%)$ & $12(10 \%)$ \\
\hline
\end{tabular}

Table 2

Overview of one-to-n mapping.

\begin{tabular}{lll}
\hline & Subset & Omaha System \\
\hline 1. & problem with menstruation & abnormal menstrual pattern \\
2. & fertility problem & infertility \\
3. & difficulty performing dressing & difficulty dressing lower body/difficulty \\
& activities & dressing upper body \\
4. & impaired touch discrimination & decreased sensation, increased sensation \\
\hline
\end{tabular}

